\title{
Strategi Menghafal Penjarian Tangga Nada dalam Mata Kuliah Instrumen Dasar I
}

\author{
Oriana Tio Parahita Nainggolan ${ }^{1}$
}

Prodi Pendidikan Musik, Institut Seni Indonesia Yogyakarta

\begin{abstract}
Scales Fingering Memorization Strategy in the Basic Instrument Course I. Scales play an important role as a fundamental basic to play piano. Studying scales will give students the opportunity not only developing hands coordination but also building the strength of hands and fingers. In doing the scales, the first thing to do is memorizing fingering on every scale, because every scale has their own fingering. The learning strategy to memorize fingering's scales is by grouping the same fingering that is use for several scales. This research aims to study the use of grouping fingering towards students learning achievement in the subject of Instrumen Dasar I at Music Education Study Program, Performing Arts Faculty, Indonesia Institute of the Arts Yogyakarta, second semester of the academic year 2017/2018. As the result of this study, it can be concluded that grouping fingering help the students to memorize scale's fingering in learning scales.
\end{abstract}

Keywords: piano; fingering; basic instrument

\begin{abstract}
ABSTRAK
Pembelajaran tangga nada merupakan materi dasar dan penting pada pembelajaran piano. Mempelajari tangga nada memberikan manfaat untuk meningkatkan kekuatan dan keterampilan jari dalam bermain piano. Untuk dapat memainkan tangga nada, hal yang harus dilakukan adalah menghafal penggunaan penjarian yang benar. Strategi pembelajaran yang digunakan dalam menghafal penjarian tangga nada adalah dengan mengelompokan penjarian. Pengelompokan penjarian adalah penggunaan penjarian yang sama pada beberapa tangga nada. Penelitian ini dilakukan untuk mengkaji penggunaan strategi pengelompokan penjarian dalam menghafal penjarian tangga nada pada mata kuliah Piano Dasar I. Penelitian ini dilakukan di Program Studi S-1 Pendidikan Musik, Fakultas Seni Pertunjukan, Institut Seni Indonesia Yogyakarta, semester genap tahun akademik 2017/2018. Hasil penelitian menunjukkan bahwa strategi pengelompokan penjarian mempermudah mahasiswa dalam menghafal penjarian tangga nada pada materi Instrumen Dasar I.
\end{abstract}

Kata kunci: piano; penjarian; instrumen dasar

\section{Pendahuluan}

Pembelajaran piano pada tingkat awal difokuskan pada latihan untuk meningkatkan keterampilan jari melalui berbagai macam latihan (Takegawa, Terada, \& Tsukamoto, 2008). Latihan yang sering digunakan untuk meningkatkan keterampilan jari adalah latihan tangga nada
(Heijink \& Meulenbroek, 2002). Berlatih tangga nada secara terus menerus, akan menghasilkan keteraturan pada penjarian (Piano fingering) yang pada akhirnya dapat meningkatkan keterampilan jari dalam bermain piano. Piano fingering adalah urutan penggunaan penjarian yang benar pada saat bermain piano sehingga menghasilkan keteraturan penjarian.

\footnotetext{
Alamat korespondensi: Program Studi Pendidikan Musik, Fakultas Seni Pertunjukan, Institut Seni Indonesia Yogyakarta. Hp.: 081328008082. E-mail: orianatioparahitangl@gmail.com.
} 
Penggunaan penjarian yang benar merupakan aspek dasar penting pada pembelajaran piano. Karena aspek piano fingering penting bagi pemula, maka sangat disarankan agar sejak awal pembelajaran piano, hal ini diajarkan dengan benar. Bagi pemula untuk dapat memainkan tangga nada dengan baik dan benar, maka urutan penjarian harus dihafal terlebih dahulu.

Dalam menghafal penjarian yang benar pada latihan tangga nada dibutuhkan sebuah strategi agar dapat dihafal dengan efektif dan efisien. Strategi yang digunakan adalah dengan mengelompokan penjarian yang sama pada beberapa tangga nada. Pengelompokan penjarian yang sama digunakan untuk mempermudah pemula dalam menghafal dan memainkan tangga nada.

Strategi pengelompokan penjarian digunakan pada pembelajaran Instrumen Dasar I (Piano Dasar I) di Program Studi (Prodi) S-1 Pendidikan Musik, Fakultas Seni Pertunjukan (FSP), Institut Seni Indonesia (ISI) Yogyakarta. Strategi pembelajaran ini diharapkan dapat membantu mahasiswa yang berada pada tingkat pemula dalam menghafal penjarian tangga nada dan memainkannya dengan penjarian yang benar, serta pada akhirnya dapat meningkatkan keterampilan bermain piano. Peningkatan keterampilan dibutuhkan bagi mahasiswa pada perguruan tinggi seni, termasuk bidang musik, karena sebagian besar mata kuliah merupakan mata kuliah vokasional yang berdasar pada keterampilan individual (A. Indrawan, 2015).

Sebagai gambaran, mata kuliah Instrumen Dasar I merupakan mata kuliah yang harus ditempuh oleh mahasiswa semester II Program Studi (Prodi) Pendidikan Musik, yang instrumen mayornya bukan instrumen piano, sehingga mahasiswa Prodi S-1 Pendidikan Musik yang menempuh mata kuliah Instrumen Dasar I diaktegorikan sebgai pemula (Gunara, 2017). Kredit yang diberikan pada mata kuliah ini adalah dua (2) SKS, dengan jumlah tatap muka satu (1) kali per minggu. Karena bersifat praktik, maka pembelajaran Instrumen Dasar I bersifat individual, yaitu satu mahasiswa dan satu orang dosen pengampu mata kuliah.

\section{Tangga Nada}

Tangga nada berasal dari Bahasa Italia scala yang berarti tangga. Pengertian tangga nada: " $A$ series of single notes progressing up or down stepwise" (urutan nada naik dan turun)(Kennedy, 2004). Tangga nada merupakan kumpulan nada-nada dalam satu oktaf nada (delapan nada) yang terdiri dari dari beberapa interval dan membentuk musik (Gill \& Purves, 2009). Dalam Kamus Besar Bahasa Indonesia, tangga nada adalah peraturan nada yang menaik-naik bunyinya (Kemendikbud, n.d.)

Tangga nada yang digunakan pada pembelajaran piano adalah tangga nada diatonis. Tangga nada diatonis merupakan tangga nada yang terdiri dari tujuh buah nada (Aprilinda \& Ariani, 2016). Tangga nada diatonic terdiri dari dua tangga nada yaitu tangga nada mayor dan tangga nada minor (Wulandari, 2015). Tangga nada mayor dan tangga nada minor adalah dua tangga nada yang sering digunakan dalam musik. Tangga nada mayor dan minor merupakan urutan nada yang terdiri dari delapan nada (Laycock, 2016). Urutan delapan nada, dalam musik disebut oktaf. Dalam penulisan notasi musik, pola tangga nada akan ditulis urutan nada naik dan turun.

Dalam sebuah tangga nada terdapat unsur penting pembentuk tangga nada yaitu interval. Interval merupakan jarak antar dua nada. Interval yang digunakan sebagai pembentuk tangga nada adalah interval yang berjarak satu (tones) dan interval yang berjarak setengah (semitones). Urutan interval yang digunakan pembentuk pola tangga nada (Purnomo, 2018).

Notasi 1. Tangga nada.

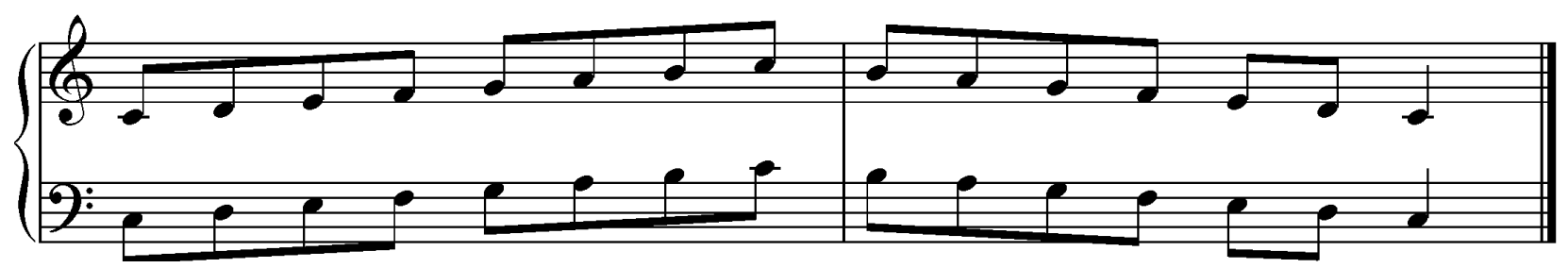


Pola interval yang digunakan dalam tangga nada mayor adalah terdapat dua buah interval berjarak setengah yaitu nada 3-4 serta nada 7-8, atau biasa ditulis seperti pada notasi 2 .

Pola interval pada tangga nada minor agak berbeda dari pola interval pada tangga nada mayor. Pola interval yang digunakan pada tangga nada minor dibagi menjadi empat pola interval. Setiap pola interval mewakili satu jenis tangga nada minor. Empat pola tersebut adalah: 1) Pola interval tangga nada minor natural: $1-1 / 2-1-1-1 / 2-1-1$ (Pangerang, Hidayatno, \& Zahra, 2015); 2) Pola interval tangga nada minor harmonis: $1-1 / 2-1$ - $1-1 / 2-1 \frac{1}{1 / 2}-1 / 2$ (B. Indrawan, Sumaryanto, \& Sunarto, 2016); 3) Pola interval pada tangga nada minor melodis terdapat dua macam yaitu pola naik dan turun. Pola interval naik pada tangga nada minor melodis: $1-1 / 2-1-1-1-1-1 / 2$, sedangkan pola interval turunnya: $1-1-1 / 2-1-$ $1-1 / 2-1$; dan 4) Pola interval tangga nada minor Zygana: $1-1 / 2-1 \frac{1}{2}-1 / 2-1 / 2-1 \frac{1}{2}-1 / 2$. Notasi 3 sampai dengan notasi 6 merupakan pola interval tangga nada.

Tidak semua tangga nada dapat digunakan pada pembelajaran Instrumen Dasar I. Pembelajaran Instrumen Dasar I hanya menggunakan dua tangga nada yaitu tangga nada mayor dan minor harmonis. Tangga nada minor melodis digunakan pada pembelajaran piano tingkat menengah.

Dalam Teori Musik, terdapat 14 tangga nada mayor dan 14 tangga nada minor, maka secara keseluruhan terdapat 28 tangga nada. Kesemua tangga nada tersebut, merupakan tangga nada yang harus dihafal dan dapat dimainkan dengan penjarian yang benar pada pembelajaran piano. Pada pembelajaran Instrumen Dasar I, tidak semua

Notasi 2. Tangga nada mayor.

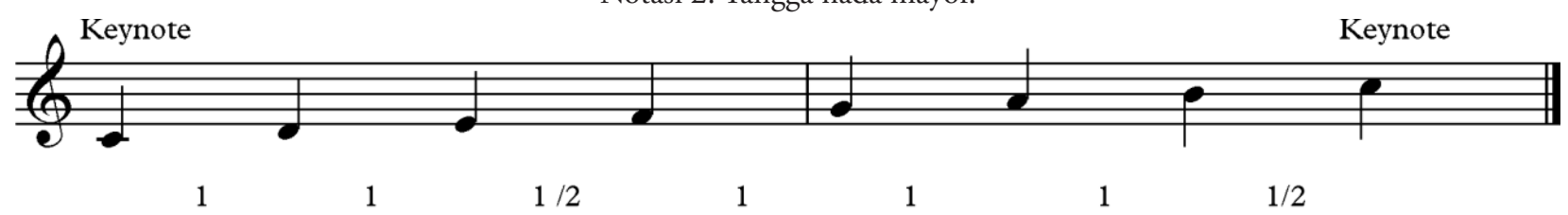

Keterangan:
Keynote $=$ nada awal

\section{Notasi 3. Tangga nada minor natural.}

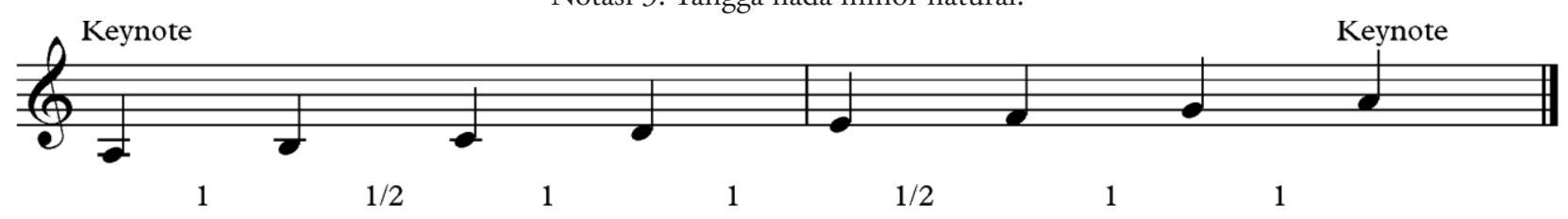

Notasi 4. Tangga nada minor harmonis.

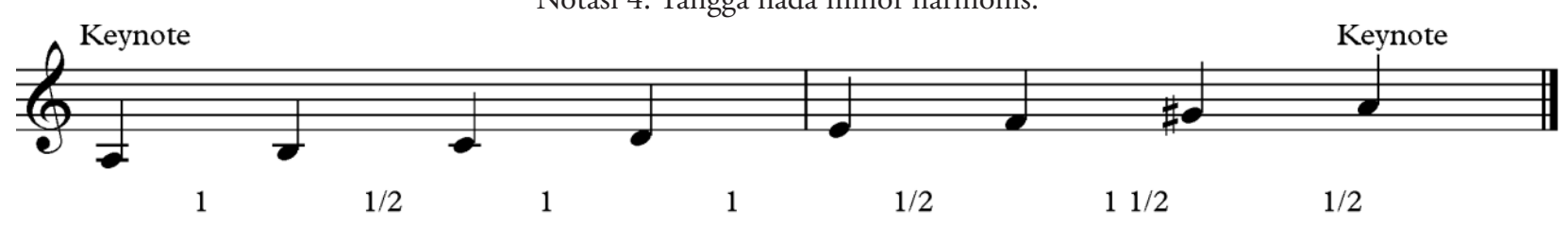

Notasi 5. Tangga nada minor melodis.

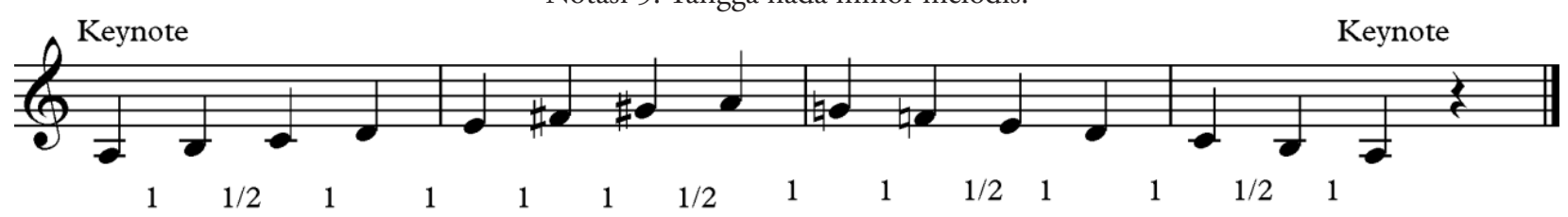

Notasi 6. Tangga nada minor Zygana.

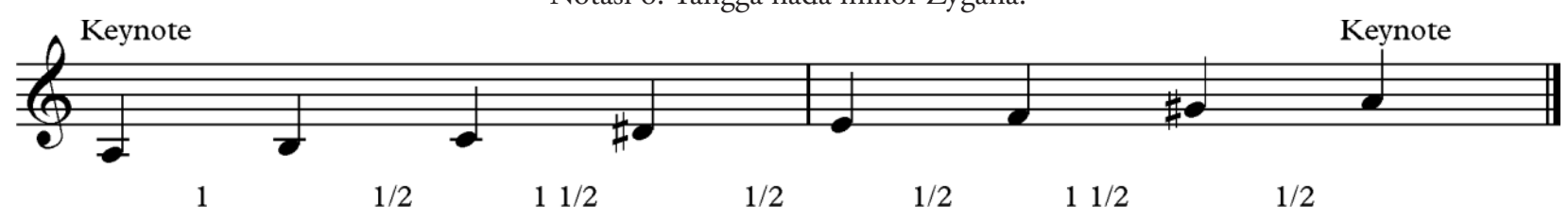


tangga nada dipelajari. Tangga nada yang dipelajari pada perkuliahan Instrumen Dasar I adalah tangga nada $C, G, D$, dan F mayor serta tangga nada $A$, $\mathrm{E}$, dan $\mathrm{D}$ minor harmonis.

Tangga nada pada pembelajaran piano merupakan dasar dimana teknik permainan piano dan teori musik digunakan secara bersamaan untuk membangun pemahaman terhadap permainan piano. Selain mendapat pemahaman tentang permainan piano, bagi para pemula, mempelajari tangga nada memberikan banyak manfaat, seperti:

a. Meningkatkan koordinasi kedua tangan.

b. Meningkatkan akurasi pada saat bermain lagu dalam tempo yang cepat.

c. Meningkatkan kekuatan jari.

d. Meningkatkan kemampuan penguasaan keyboard.

e. Memainkan tangga nada meningkatkan kemampuan murid dalam menghafal 24 tangga nada.

f. Latihan tangga nada meningkatka kepekaan ritme, artikulasi dan kecepatan (Spanswick, 2012).

\section{Penjarian}

Penjarian merupakan keterampilan penting pada pembelajaran piano, khususnya pada awal pembelajaran (Wei, 2016). Penjarian atau fingering merupakan istilah penomoran jari pada saat bermain instrumen musik. Dalam pembelajaran piano, penjarian merujuk pada penggunaan jari yang tepat (Balliauw, Herremans, Cuervo, \& Sörensen, 2015). Materi awal dari penggunaan jari yang tepat adalah menghafal penjarian pada latihan tangga nada. Menghafal penjarian pada tangganada dimaksudkan agar dapat menemukan pola penjarian yang benar dan keteraturan penjarian.

Penomoran penjarian piano dilakukan berdasarkan urutan jari. Terdapat lima nomor pada

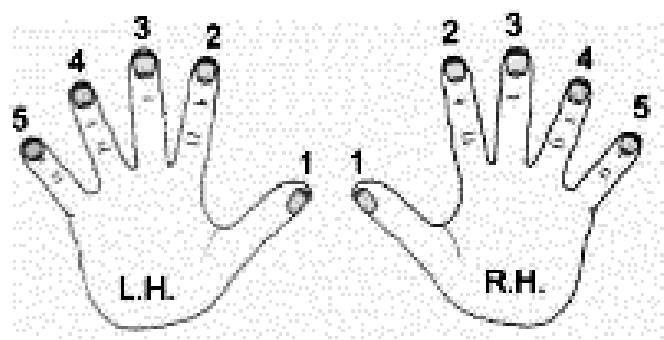

Gambar 1. Penomoran jari.

(Sumber: http://www.keytarhq.com/piano-fingering.html) penjarian piano: 1) Nomor 1 adalah jari jempol; 2) Nomor 2 adalah jari telunjuk; 3) Nomor 3 adalah jari tengah; 4) Nomor 4 adalah jari manis; dan 5) Nomor 5 adalah jari kelingking. Penomoran jari tangan kanan dan tangan kiri menggunakan sistem yang sama pada penjarian piano.

Penggunaan penjarian dalam pembelajaran piano memiliki tujuan utama yaitu menolong agar pemain piano dapat memainkan piano dengan mudah dan tanpa membuang tenaga yang berlebih (Mulyanto, 2008). Artinya adalah bahwa penjarian digunakan untuk membentuk efisiensi dan efektivitas dalam bermain piano (Kodijat, 2008). Sangat disarankan apabila mempelajari sebuah lagu yang baru, agar dapat mencermati penjarian yang akan digunakan. Dalam beberapa buku piano tertulis penjarian yang digunakan, namun terkadang penjarian tersebut tidak sesuai dengan anatomi jari semua pemain piano, sehingga pemain piano diharapkan dapat merubah penjarian tersebut sesuai dengan anatomi jari pemain piano.

Proses pertama yang harus dilakukan oleh pemain piano untuk mendapat posisi jari yang fleksibel adalah dengan memberi penomoran jari. Hal ini dilakukan diawal karena memori otot (muscle memory) akan aktif saat pertama kali memainkan piano. Memori otot adalah memori yang akan membentuk hafalan otomatis pada otot (Shusterman, 2011). Memori otot penting pada saat bermain piano, karena dapat membuat efisien pada permainan piano. Namun memori otot memiliki dampak negatif apabila tidak digunakan dengan baik dan benar, misalnya apabila belajar sebuah lagu baru dengan menggunakan penjarian yang salah, maka penjarian yang salah tersebut akan diingat dan akan memakan waktu yang lama untuk membetulkan penjarian tersebut, maka diharapkan pemain piano mencermati penggunaan penjarian yang fleksibel dan nyaman sesuai dengan anatomi jari pemain piano tersebut sehingga permainan piano menjadi lebih efisien dan efektif. Apabila penggunaan penjarian dirasa tidak memberikan fleksibelitas dan kenyamanan, maka sebaik penggunaan jari tersebut harus diganti diawal. Apabila penggunaan jari yang tidak diganti diawal maka, memori otot akan menghafal penjarian tersebut, sehingga pada akhirnya permainan 
piano menjadi tidak berkembang (https://www. onlinepianocoach.com/piano-fingering.html).

Dalam mencari penjarian yang efektif dan efisien perlu dilakukan latihan berulangulang. Pemilihan penjarian biasanya dilakukan berdasarkan aspek ergonomis seorang pemain (Parncutt, Sloboda, Clarke, Raekallio, \& Desain, 1997). Latihan yang dilakukan secara terus menerus akan meningkatkan keterampilan jari (Wirayudha, 2014). Selain latihan berulang-ulang, terdapat aturan dasar yang sering dijadikan panduan dalam penggunaan penjarian pada piano:

a. Hindari penggunaan jari jempol (1) pada tuts keyboard warna hitam. Hal ini dikarenakan jari jempol merupakan jari yang pendek diantara jari yang lain, maka akan tidak efektif jika digunakan pada tuts keyboard warna hitam. Jari jempol dapat digunakan secara khusus, terutama pada lagu yang banyak menggunakan tuts keyboard warna hitam.

b. Pelajari pola penjarian dasar. Pola penjarian dasar pada permainan piano ada pada latihan tangga nada dan trinada. c. Carilah penjarian yang dapat bertahan lama tanpa mengganti posisi tangan.

d. Penjarian harus dapat membantu pemain dalam mengekspresikan musik yang dimainkan.

\section{Pengelompokan Penjarian}

Pengelompokkan penjarian yang dimaksud dalam penelitian ini adalah penggunaan penjarian yang sama untuk beberapa tangga nada. Pada materi perkuliahan Instrumen Dasar I, penggunaan penjarian yang sama terdapat pada tangga nada $C$, G, D, F, mayor dan A, E, D minor. Semua tangga nada ini menggunakan penjarian yang sama.

Pengelompokan penjarian pada tangga nada yang digunakan dalam materi pembelajaran Piano Dasar I dapat dilihat pada notasi 7 sampai dengan notasi 13.

Keseluruh tangga nada tersebut menggunakan penjarian yang sama. Agar dapat mempermudah untuk melihat kesamaan penggunaan jari pada tangga nada diatas, maka akan dituliskan pada tabel 1 .

Notasi 7. Tangga nada $\mathrm{C}$ mayor.

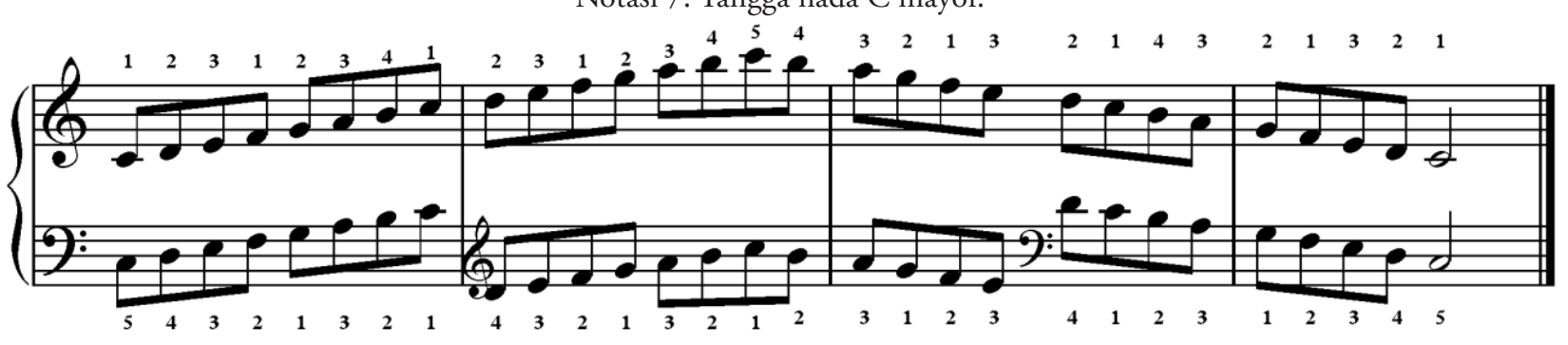

Notasi 8. Tangga nada G mayor.

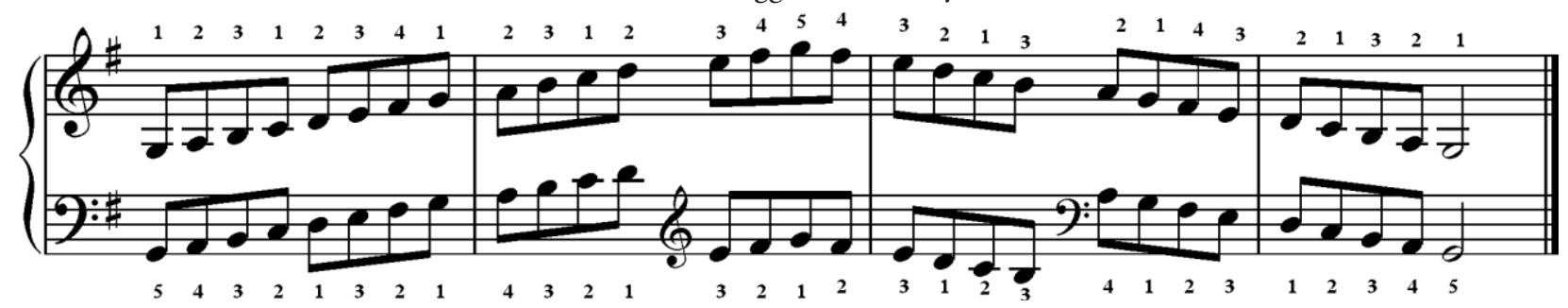

Notasi 9. Tangga nada D mayor.

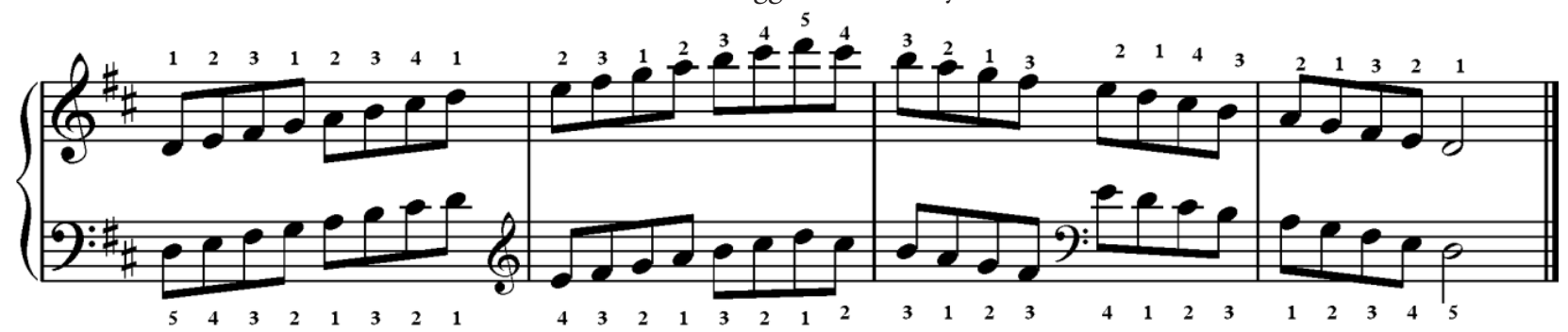


Notasi 10. Tangga nada F mayor.

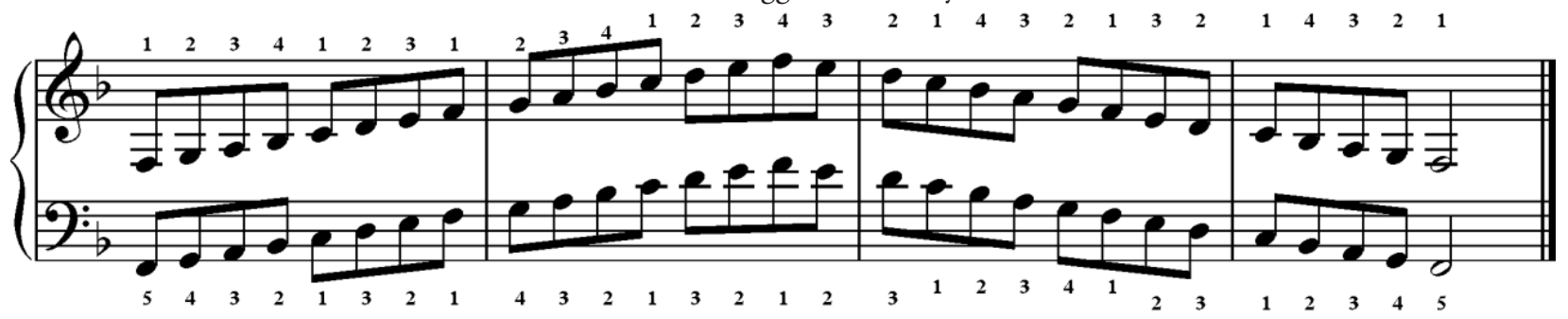

Notasi 11. Tangga nada A minor.

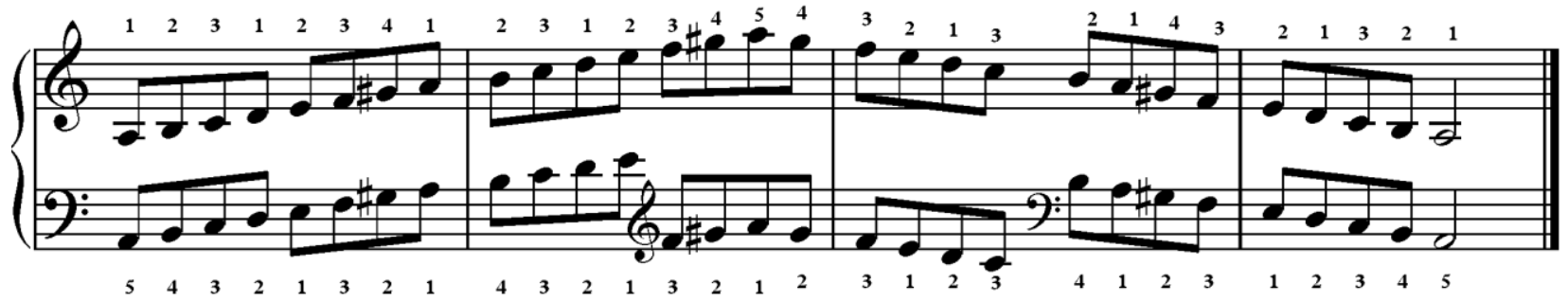

Notasi 12. Tangga nada E minor.

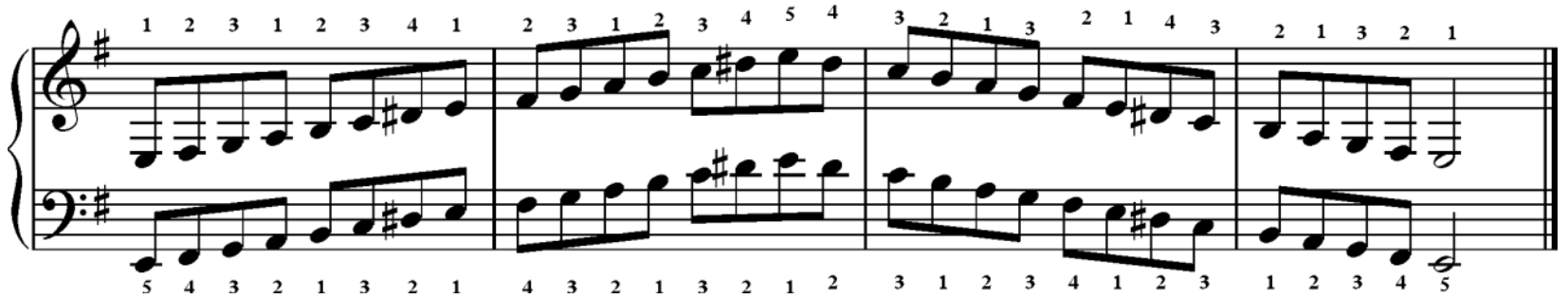

Notasi 13. Tangga nada D minor.

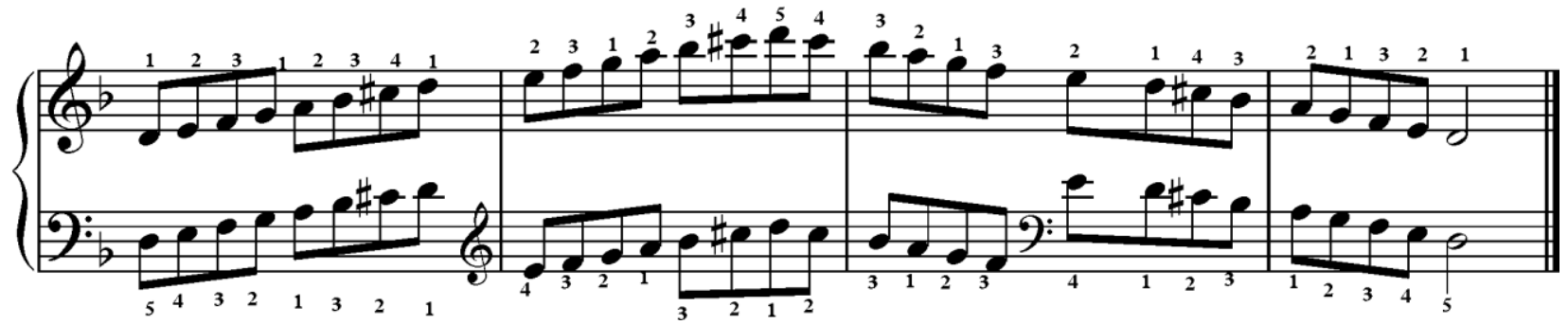

Tabel 1. Pengelompokan penjarian.

\begin{tabular}{|c|c|}
\hline \multirow{2}{*}{$\frac{\text { No } \quad \text { Nama Tangga Nada }}{\text { 1. Tangga Nada C Mayor }}$} & Penjarian yang Digunakan \\
\hline & Kanan: $\quad 1-2-3-1-2-3-4-5$ \\
\hline & Kiri : $5-4-3-2-1-3-2-1$ \\
\hline 2. Tangga Nada G Mayor & Kanan: $\quad 1-2-3-1-2-3-4-5$ \\
\hline & Kiri : $5-4-3-2-1-3-2-1$ \\
\hline 3. Tangga Nada D Mayor & Kanan: $\quad 1-2-3-1-2-3-4-5$ \\
\hline & Kiri : $5-4-3-2-1-3-2-1$ \\
\hline 4. Tangga Nada F Mayor & Kanan: $\quad 1-2-3-4-1-2-3-4$ \\
\hline & Kiri : $5-4-3-2-1-3-2-1$ \\
\hline 5. Tangga Nada A Minor & Kanan: $\quad 1-2-3-1-2-3-4-5$ \\
\hline & Kiri : $5-4-3-2-1-3-2-1$ \\
\hline 6. Tangga Nada E Minor & Kanan: $\quad 1-2-3-1-2-3-4-5$ \\
\hline & Kiri : $5-4-3-2-1-3-2-1$ \\
\hline 7. Tangga Nada D Minor & Kanan: $\quad 1-2-3-1-2-3-4-5$ \\
\hline & Kiri : $5-4-3-2-1-3-2-1$ \\
\hline
\end{tabular}

Keterangan: Pada kolom penjarian yang digunakan, wilayah nada yang digunakan hanya satu oktaf 
Pada tabel tersebut dapat terlihat bawah seluruh tangga nada yang digunakan pada pembelajaran Piano Dasar I selalu dimulai dengan menggunakan jari 1 pada tangan kanan dan menggunakan jari 5 pada tangan kiri. Pada saat terjadi perputaran penjarian, maka pada tangan kanan digunakan jari 3, dan tangan kiri menggunakan jari 3. Hanya pada tangga nada $\mathrm{F}$ mayor perputaran penjarian pertama menggunakan jari 4 , hal ini dikarenakan pada tangga nada F mayor, nada ke-4 adalah nada Bb yang berada pada tuts keyboard warna hitam, maka penjarian pada nada $\mathrm{Bb}$ harus menghindari penggunaan jari 1, sehingga perputaran penjarian digunakan jari 4 terlebih dahulu dan diikuti dengan jari 1. Hal ini juga berakibat pada penggunaan penjarian di akhir nada, yaitu dengan menggunakan jari 4. Meskipun terdapat perbedaan penjarian, namun prinsip yang digunakan dalam penjarian tersebut sama seperti pada tangga nada C, G, D Mayor dan A, E, D Minor.

Berdasarkan penggunaan jari yang dijelaskan pada tabel 1, maka terdapat beberapa kesimpulan dalam penggunaan jari, yaitu: 1) Jari 1 (tangan kanan) dan jari 5 (tangan kiri) hanya digunakan pada nada awal dan nada terakhir dari urutan nada pada tangga nada; 2) Penggunaan jari untuk tuts hitam digunakan jari yang panjang; 3) Perputaran jari pada tangan kanan menggunakan perpindahan jari 3 ke jari 1; dan 4) Perputaran jari pada tangan kiri menggunakan perpindahan jari 1 ke jari 4 .

\section{Penutup}

Hasil penelitian ini menunjukkan bahwa strategi pengelompokan penjarian pada pembelajaran Instrumen Dasar I mempermudah dalam menghafal penjarian pada permainan tangga nada. Pengelompokan penjarian tangga nada ini didasarkan pada: 1) Penggunaan penjarian pada tangan kanan dan tangan kiri yang sama yang dimulai pada jari 1 pada tangan kanan dan jari 5 pada tangan kiri; 2) Penggunaan penjarian yang sama terdapat juga pada perputaran penjarian pada tangan kanan dan tangan kiri; 3) Pengelompokan penjarian dilakukan berdasarkan pola interval nada.

\section{Kepustakaan}

Aprilinda, Y., \& Ariani, F. (2016). Aplikasi Tuner Guitar Berbasis Android untuk Membantu dalam Bermain dan Menyetel Gitar. EXPLORE, 6(2).

Balliauw, M., Herremans, D., Cuervo, D. P., \& Sörensen, K. (2015). Generating fingerings for polyphonic piano music with a tabu search algorithm. In International Conference on Mathematics and Computation in Music (pp. 149-160). Springer.

Gill, K. Z., \& Purves, D. (2009). A biological rationale for musical scales. PLoS One, 4(12), e8144.

Gunara, S. (2017). Pemanfataan Bahan Sight Reading Dalam Pembelajaran Piano. RITME, 2(1), 78-84.

Heijink, H., \& Meulenbroek, R. G. J. (2002). On the complexity of classical guitar playing: functional adaptations to task constraints. Journal of Motor Behavior, 34(4), 339-351.

Indrawan, A. (2015). Adaptasi Konserto pada Ensambel Gitar sebagai Upaya Pengayaan Bahan Ajar Matakuliah Ensambel. Resital: Jurnal Seni Pertunjukan, 16(2).

Indrawan, B., Sumaryanto, T., \& Sunarto, S. (2016). Bentuk Komposisi Dan Pesan Moral Dalam Pertunjukan Musik Kiai Kanjeng. Catharsis, 5(2), 114-122.

Kemendikbud. (n.d.). Tangga Nada. Retrieved November 6, 2018, from https://kbbi.web. id/tangga

Kennedy, M. (2004). Oxford Concise Dictionary of Music (4th ed.).

Kodijat, L. (2008). Penuntun Mengajar Piano. Jakarta: Djambatan.

Laycock, K. (2016). Uncertain harmonies (or fall) Colour scales and cadences. Colour Scales and Cadences. Journal of the International Colour Association, 15(20), 31-41.

Mulyanto, E. S. (2008). Panduan Dasar Bermain Jazz. Jakarta: Kawan Pustaka.

Pangerang, A., Hidayatno, A., \& Zahra, A. A. (2015). Perancangan Aplikasi Pengenalan 
Chord Instrumen Tunggal Menggunakan Transformasi Wavelet Dan Key Detection. TRANSIENT, 4(1), 31-38.

Parncutt, R., Sloboda, J. A., Clarke, E. F., Raekallio, M., \& Desain, P. (1997). An ergonomic model of keyboard fingering for melodic fragments. Music Perception: An Interdisciplinary Journal, 14(4), 341-382.

Purnomo, T. W. (2018). Studi DeskriptifTeks dan Konteks Musik Tradisional Irish Uilleann Pipes Pada Lagu The Gender in The Pratie Hole. Gondang: Jurnal Seni Dan Budaya, 1(2), 49-62.

Shusterman, R. (2011). Muscle memory and the somaesthetic pathologies of everyday life. Human Movement, 12(1), 4-15.

Spanswick, M. (2012). 6 Reasons Why You Need To Practice Them. Retrieved September
20, 2018, from https://melaniespanswick. com/2012/03/07/scales-6-reasons-why-youneed-to-practice-them/

Takegawa, Y., Terada, T., \& Tsukamoto, M. (2008). A piano learning support system considering rhythm. Journal, Vol, 32(1), 9-25.

Wei, L. I. (2016). Important Role of Basic Finger Training in Piano Learning. Cross-Cultural Communication, 12(5), 66-72.

Wirayudha, A. H. (2014). A Solution to the Fingering Problem of Brahms Cellos Sonata No. 1 Opus 38 and Shostakovich Cello Sonata Opus 40. Resital: Jurnal Seni Pertunjukan, 15(1), 100-106.

Wulandari, R. (2015). Nada Diatonik Pada Gelas Kaca Terkait Tingkat Pencapaian Perkembangan Motorik Halus Pada Anak usia Dini. Jurnal Pendidikan Anak, 4(2). 


\section{WRITING INSTRUCTIONS}

\section{Title}

[Title must succinctly describes the contents of the research article and attract the academic readers. The title consists of 8-12 words, not including definite article (the) and indefinite article ( $a$, an). Use the phrases, not sentence.].

\section{Author(s)}

[Author must fill out author's profile that consist of author First, Middle and Last Name (If author only uses one name, fill the first name and last name with the same name), Gender, Initial, Username, Password, Affliation (University/Institution), E-mail, Mailing Address (complete address of affliation), Country and Bio Statement. Author(s) must follow the journal template which can be downloaded at http://journal.isi.ac.id/index.

\section{php/resital}

\section{ABSTRACT}

The abstract is a summary of the article. It is consist of aim/goal/problem of research, research methods, results and discussion, and conclusion. Implications or recommendation can be added in the abstract. The abstract must be written in 150-250 words. The abstract must not contain lengthy background information and have no reference to figure, table, equation, any bibliographical reference either coming within or other article. The language of abstract must be clear and concise. It is a stand-alone summary in one paragraph.

Keywords: it contains 3-5 important words that are taken from the title and the content of the paper

\section{Introduction}

The introduction show what is already known from the previous studies, defines the importance of the study, literature review, and state the research question. In order to understand what is already known from the previous study, the introduction must consist of discussing the relevant journal article (with citation) and summarizing the current understanding of the problem encounter. The methods explain clearly how the author carried out the research. The method must describe the research design clearly, the replicable research procedures, describe how to summarize and analyze the data.

\section{Result and Discussion}

The result section shows objectively the presentation of the research key results without any interpretation using text, tables and figures. The result section begins with text, presenting the key finding, and referring to the tables and figures. The table must not print screen, specific numerical values, compare and contrast values, and minimum of 2 row and column. The figures must clear (provide original file as supplementary file in article submission), highlight trends, pattern, and relationship. The result section must present how the author ensure the data validity and reliability

The discussion section shows how the author interprets the results in light of what are already known, and to explain the new understanding of the problem after taking your results into consideration. The discussion must connect with the Introduction so it tells how your study contributes to the body of knowledge and society.

Tabel 1. Student Distribution Frequency

\begin{tabular}{ccccc}
\hline No. & Interval & Frequency & $\%$ & Category \\
\hline 1. & $85-100$ & 59 & 28.36 & Very Good \\
2. & $75-84$ & 93 & 44.71 & Good \\
3. & $65-74$ & 37 & 17.78 & Average \\
4. & $55-65$ & 19 & 09.15 & Bad \\
\hline \multicolumn{2}{c}{ Jumlah } & 208 & 100.00 & \\
\hline
\end{tabular}

Eb major

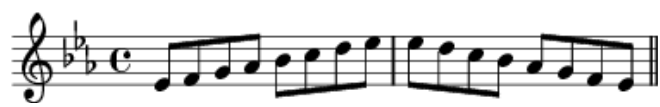

Figure 1. Speed Changing Tool

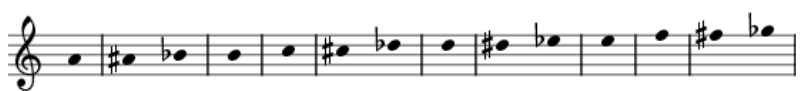

$A_{4} \quad A_{4} / H_{4} / B_{4} \quad B_{4} \quad C_{5} \quad C_{3} / H_{5} \quad D_{5} \quad D_{H_{5}} / E_{5} \quad E_{5} \quad F_{5} \quad F_{H_{5}} / \mathrm{Gb}_{5}$
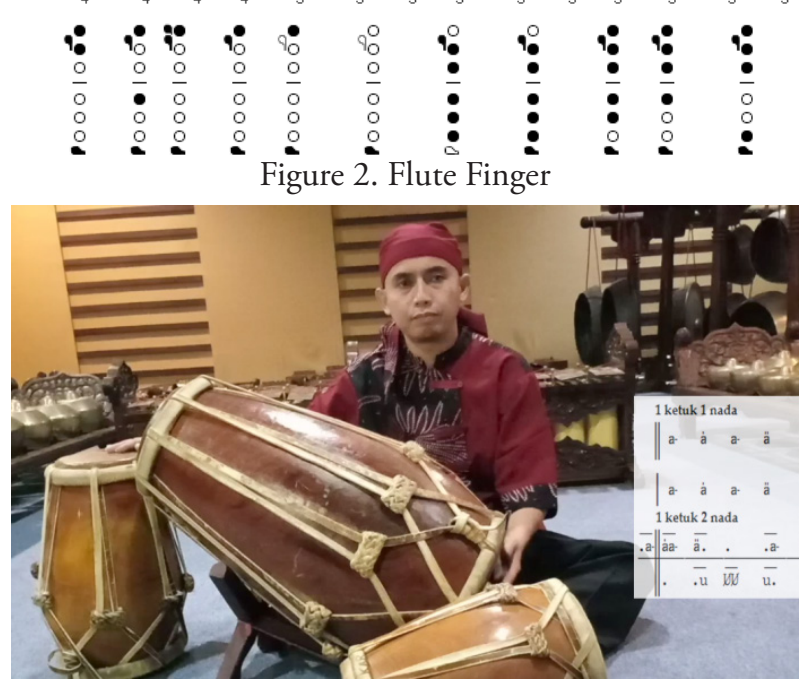

Figure 3. Kendang Practice (Source: Asep, 2017) 


\section{Conclusion}

The conclusions section show the answer or clarification of the research questions and opportunities for future research.

\section{References}

The reference must consist of $80 \%$ from relevant and recent primary sources (such as article of journal or conference from last 5 years). The reference must be written in APA style and using reference manager software Mendeley.

\section{Journal Article}

B Budi, D. S. U., Soedarsono, R. M., Haryono, T., \& Narawati, T. (2014). Angklung Dogdog Lojor pada Upacara Seren Taun. Resital: Jurnal Seni Pertunjukan, 15(2), 139-151. Retrieved from http://www.journal.isi.ac.id/index.php/ resital/article/view/848.

\section{Book}

Suharto, Edi. (2014). Membangun Masyarakat Memberdayakan Rakyat: Kajian Strategis Pembangunan Kesejahteraan Sosial \& Pekerjaan
Sosial. Bandung: Refika Aditama.

\section{Thesis, Dissertation, and Research Reports}

Prasetya, H.B. (2012). Melesed dan Nggandhul dalam Karawitan Pedalangan Gaya Yogyakarta. Universitas Gadjah Mada Yogyakarta.

\section{Conference Proceedings}

Muthmainnah, L. (2017). Perancangan Kampanye Penanggulangan Dampak Lagu Dewasa Terhadap Anak-Anak. e-Proceeding of Art and Design, 4(2), 138-146.

\section{Audio/Video}

Sugito, Hadi. (2005). Lakon Semar Gugat. (Cassete). Semarang: Fajar Record.

\section{Informant}

Handiman (79 years old). Angklung Craftman who is the student of Daeng Sietigna. Jln. Surapati No. 95 Bandung 40123.

\section{Article Submission}

Article should be uploaded through Open Journal System of http://journal.isi.ac.id/index.php/resital 